\title{
Health anxiety status of elite athletes in COVID-19 social isolation period
}

\author{
Ozen $\mathrm{G}^{1}$, Koc $\mathrm{H}^{2}$, Aksoy $\mathrm{C}^{3}$ \\ Department of Physical Education and Sports Teacher Education, Faculty of Sport Sciences, Canakkale \\ Onsekiz Mart University, Canakkale, Turkey. gokmenozen44@gmail.com
}

\begin{abstract}
AIM: The aim of this study is to examine the health anxiety states and behaviours of athletes during the social isolation period due to COVID-19 pandemic.

METHODS: 250 elite athletes participated in the study. 154 of the participants were males and 96 were females. Health Anxiety Scale was used to determine the health anxiety states of the participants in the COVID-19 pandemic process.

RESULTS: Our findings revealed that athletes who were tested for COVID-19 and who thought they had symptoms of the disease had higher levels of health anxiety and athletes who reported a temporary loss in athletic performance had higher disease anxiety.

CONCLUSIONS: The results of this study showed that the COVID-19 pandemic and social isolation process have some effects on athletes' health anxiety. It will be beneficial to provide psychological support in this period for athletes to have a fast return to competitions and match after the pandemic (Tab. 5, Ref. 24). Text in PDF www.elis.sk

KEY WORDS: anxiety, athletes, COVID-19, health, social isolation.
\end{abstract}

\section{Introduction}

The new type of coronavirus disease, called COVID-19, which first appeared in the Wuhan region of China in December 2019, soon spread all over the world, causing a pandemic (1). According to the data of the World Health Organization, 750,890 people suffered from this disease in March 2020 and 36,405 people died due to complications caused by the disease in the respiratory system (2). COVID-19 disease, which is accepted as the biggest epidemic in recent years, became the biggest health problem in the world shortly after its first appearance. Since a vaccine or antiviral drug against the virus causing the disease has not been developed yet, international health institutions state that the main solution to prevent the spread of the disease is personal hygiene and social isolation. Hand hygiene, use of masks and social distancing are reported as priority measures to prevent the disease $(3,4)$.

In countries where COVID-19 disease is beginning to occur, social isolation measures are taken as the priority to reduce the transmission rate of the disease. Within the scope of these

${ }^{1}$ Department of Physical Education and Sports Teacher Education, Faculty of Sport Sciences, Canakkale Onsekiz Mart University, Canakkale, Turkey, ${ }^{2}$ Department of Coaching Education, Faculty of Sport Sciences, Canakkale Onsekiz Mart University, Canakkale, Turkey, and ${ }^{3}$ School of Physical Education and Sport, Kahramanmaras Sutcu Imam University, Kahramanmaras, Turkey

Address for correspondence: G. Ozen, Canakkale Onsekiz Mart Universitesi, Spor Bilimleri Fakultesi 17000 Canakkale, Turkey.

Phone: +90.505 .6466329$ measures, people are asked not to leave their homes except for compulsory situations and to avoid physical contact with other people (5). This situation causes sudden changes in people's daily and social lives. However, scientific studies have also shown that it is difficult for people to psychologically adapt to such sudden changes in their daily lives at the same speed. This can cause a broad range of psychological problems in humans during and after the pandemic. In this regard, it is important to analyse psychological factors such as stress, anxiety and fear caused by the disease in the pandemic process, in order to protect human health during and after the pandemic process (6).

Anxiety is a natural emotion based on stress and fear, against an unpredictable or uncertain new situation in people's lives. Although anxiety is a psychological condition caused by the mood of people, it is a condition that causes hormonal changes in metabolism physically $(7,8)$. It is known that situations such as lifethreatening diseases, outbreaks, natural disasters, and war in people's lives cause anxiety levels to increase (9). While it is a feeling that has positive effects on life within normal limits, anxiety above normal is accepted as a psychological health problem that affects people mentally, physically and behaviourally. Anxiety disorders negatively affect both business and social lives of people from all walks of life $(9,10)$. It is also obvious that COVID-19 pandemic is an important condition that has increased the anxiety level of people recently. Recent scientific studies focus on the clinical effects and the pathology of the COVID-19 disease (11). However, examining the psychological effects of this disease, which affects the lives of billions of people worldwide, will be 
beneficial for human health and social recovery during and after the illness period.

During social isolation, many collective leisure time activities that people do in their free time especially sports activities, are limited (12). Sports is one of the most popular leisure activities today, considering both the number of participants and the audience. Sport has multidimensional benefits for people both as participants and audience (13). With the start of the social isolation process implemented as a measure against COVID-19 pandemic in many countries, sports competitions and races were postponed and sports facilities were closed (14). Additionally, apart from individual training of athletes, team training in clubs or teams are cancelled. Sports activities will have a great role in normalizing the social life of people after the pandemic. For this reason, it will be considered to start sports organizations in a short time that are delayed at national and international levels. However, it will definitely take a certain time for athletes to recover physically and psychologically after this detraining period in order to participate in these competitions and races (15). For this reason, determining the psychological conditions and thoughts of athletes in this pandemic and social isolation period is very important in order to ensure a faster return to sports competitions at the end of the social isolation process. For this reason, the purpose of our research is to examine the anxiety levels and sports behaviour experienced by athletes during this period due to coronavirus and social isolation.

\section{Materials and methods}

\section{Research procedure}

The study was conducted at the end of March 2020 when the number of COVID-19 cases started to increase in Turkey and sports events were ceased within the scope of social isolation. Information about the research and the data collection tools were sent to the participants via the internet in a digital environment in accordance with social isolation measures. Written informed consent forms were obtained from athletes who agreed to participate voluntarily in this study. This study was conducted according to the criteria set by the Declaration of Helsinki and ethical standards in sport and exercise science research (16).

\section{Participants}

255 elite athletes who have been active in different sports categories in 2019-2020 participated in the study voluntarily. The research group consisted of 99 (38.8\%) women and $156(61.2 \%)$ men. The average age of the participants was 23.4 years in the range of $17-40$ years. General information about the participants is presented in Table 1.

\section{Data collection}

The data for this study was obtained from a standardized data extraction form and health anxiety inventory. The standardized data extraction form was used to determine participants' gender, age, health, sports, training status, social isolation period behaviours. The Health Anxiety Scale, consisting of 18 items and 2 subdimensions, developed by Salkovskis et al. (17) and adapted to
Tab. 1. General characteristics of participants.

\begin{tabular}{lcc}
\hline Variables & $\mathrm{n}(255)$ & $(\%)$ \\
\hline Gender & & \\
Female & 99 & $(38.8)$ \\
Male & 156 & $(61.2)$ \\
\hline Sports & & \\
$\quad$ Athletics & 87 & $(34.1)$ \\
Basketball & 11 & $(4.3)$ \\
Cycling & 55 & $(21.6)$ \\
Football & 21 & $(8.2)$ \\
Handball & 51 & $(20.0)$ \\
Taekwondo & 7 & $(2.7)$ \\
Volleyball & 23 & $(9.0)$ \\
\hline Total & 255 & $(100)$ \\
\hline
\end{tabular}

Turkish Culture by Aydemir et al (18) was used to determine the health anxiety states of the participants caused by COVID-19 virus. The first dimension of the scale consisting of 14 items addresses the mental status of the participants, and the second dimension consisting of 4 items addresses the mental status of participants with the hypothesis of having the disease. The second dimension of the scale was designed on the assumption that the participants had COVID-19 coronavirus disease. The items are 4-point scale evaluated between $0-3$ points. The scale has the highest total score of 54 and the lowest of 0 , and the range of possible scores in the health anxiety sub-dimension is between 44-0, and 12-0 in the fear of illness sub-dimension. A high scale score indicates a high level of anxiety. In previous studies, the internal consistency coefficient of the scale has been reported as 0.91 .

\section{Statistical analysis}

Statistical analyses were performed with SPSS statistic software package (version 17.0, SPSS Inc., Chicago, IL, USA). Data are presented as means with a standard deviation $(\mathrm{M} \pm \mathrm{SD})$ for continuous variables and categorical variables are presented as frequency counts and percentages. A Kolmogorov-Smirnov test was used to determine the homogeneity of the data. Independentsamples t-test and One-way ANOVA tests were used to determine whether the participants' health anxiety level varied in terms of descriptive variables. The significance level was fixed at 0.05 .

\section{Results}

The findings of the health, COVID-19 disease and the total anxiety scores obtained from the participants' health anxiety scale are presented in Table 2 .

The general characteristics of the participants, an analysis of their health anxiety status according to COVID-19 and their training status are presented in Table 3 . According to the results

Tab. 2. Health anxiety scale scores of the participants.

\begin{tabular}{lccc}
\hline Domain & $\mathrm{M} \pm \mathrm{SD}$ & Min & Max \\
\hline Health Anxiety & $10.64 \pm 4.5$ & 1 & 28 \\
COVID-19 Anxiety & $3.93 \pm 2.7$ & 0 & 12 \\
\hline Total Anxiety & $14.58 \pm 5.8$ & 3 & 36 \\
\hline
\end{tabular}


Tab. 3. Evaluation of the general health anxiety states of the participants.

\begin{tabular}{|c|c|c|c|c|c|}
\hline & & \multirow{2}{*}{$\%$} & \multirow{2}{*}{$\begin{array}{l}\text { Health Anxiety (14 items) } \\
\qquad \mathrm{M} \pm \mathrm{SD}\end{array}$} & \multicolumn{2}{|c|}{ Significance } \\
\hline & & & & $\mathrm{Z} / \mathrm{T} / \mathrm{F} / \mathrm{X}^{2}$ & $\mathrm{p}$ \\
\hline \multicolumn{6}{|l|}{ Gender } \\
\hline Female & 99 & $(38.8)$ & $10.51 \pm 4.7$ & \multirow{2}{*}{0.387} & \multirow{2}{*}{0.70} \\
\hline Male & 156 & $(61.2)$ & $10.73 \pm 4.4$ & & \\
\hline \multicolumn{6}{|l|}{ COVID-19 Test } \\
\hline No Test & 234 & $(91.8)$ & $10.13 \pm 4.2$ & \multirow{3}{*}{-5.882} & \multirow{3}{*}{$<0.01 *$} \\
\hline Negative & 21 & $(8.2)$ & $16.33 \pm 3.8$ & & \\
\hline Positive & 0 & $(0)$ & & & \\
\hline \multicolumn{6}{|l|}{ Symptoms of COVID-19 } \\
\hline Yes & 22 & $(8.6)$ & $13.36 \pm 4.6$ & \multirow{2}{*}{-2.979} & \multirow{2}{*}{$0.003 *$} \\
\hline No & 233 & $(91.4)$ & $10.39 \pm 4.4$ & & \\
\hline \multicolumn{6}{|l|}{ Fear of COVID-19 } \\
\hline None & 49 & (19.2) & $10.20 \pm 4.8$ & \multirow{3}{*}{1.257} & \multirow{3}{*}{0.29} \\
\hline Some & 142 & $(55.7)$ & $11.04 \pm 4.6$ & & \\
\hline Much & 64 & $(25.1)$ & $10.09 \pm 4.1$ & & \\
\hline \multicolumn{6}{|l|}{ Chronic Disease } \\
\hline Yes & 27 & $(10.6)$ & $10.89 \pm 4.6$ & \multirow{2}{*}{-0.361} & \multirow{2}{*}{0.72} \\
\hline No & 228 & $(89.4)$ & $10.61 \pm 4.5$ & & \\
\hline \multicolumn{6}{|l|}{ Acute Disease } \\
\hline Yes & 25 & $(9.8)$ & $11.16 \pm 4.6$ & \multirow{2}{*}{-0.722} & \multirow{2}{*}{0.47} \\
\hline No & 230 & $(91.2)$ & $10.59 \pm 4.5$ & & \\
\hline \multicolumn{6}{|l|}{ Training Status } \\
\hline Regular & 115 & $(45.1)$ & $10.35 \pm 4.6$ & \multirow{3}{*}{1.377} & \multirow{3}{*}{0.50} \\
\hline Irregular & 111 & $(43.5)$ & $10.94 \pm 4.6$ & & \\
\hline No training & 29 & $(11.4)$ & $11.00 \pm 3.7$ & & \\
\hline \multicolumn{6}{|l|}{ Traning Style } \\
\hline With teammates & 57 & $(22.4)$ & $10.05 \pm 4.2$ & \multirow{3}{*}{1.044} & \multirow{3}{*}{0.35} \\
\hline With Personel trainer & 40 & $(15.7)$ & $11.27 \pm 4.9$ & & \\
\hline Alone & 129 & $(50.6)$ & $10.22 \pm 4.4$ & & \\
\hline \multicolumn{6}{|c|}{ Athletic Performance Status } \\
\hline Serious loss & 65 & $(25.5)$ & $10.15 \pm 4.8$ & \multirow{4}{*}{0.522} & \\
\hline Temporary loss & 88 & $(34.5)$ & $11.06 \pm 4.0$ & & 067 \\
\hline Minor loss & 68 & $(26.7)$ & $10.51 \pm 4.3$ & & 0.01 \\
\hline No loss & 34 & $(13.3)$ & $10.76 \pm 5.7$ & & \\
\hline
\end{tabular}

0.05). However, in the comparisons made in terms of athletic performance situations, statistically significant differences were found in the mean scores of the hypochondriac anxiety $(\mathrm{p}<0.05)$. According to the results of the analysis, it was determined that the coronavirus anxiety score means were significantly higher in participants who stated a temporary performance loss $(4.51 \pm 2.8)$ than the participants who stated they experienced a minor performance loss $(3.23 \pm 2.3)$ $[\mathrm{MD}=1.18, \mathrm{z}=-5.88, \mathrm{p}<0.01]$. Also, the participants who stated having COVID-19 disease symptoms $(13.36 \pm 4.6)$ were found to have significantly higher mean scores in general health anxiety than the participants who did not have symptoms $(10.39 \pm 4.4)$ $[\mathrm{MD}=2.97, \mathrm{f}=2.853, \mathrm{p}=0.038]$.

The general characteristics of the participants, an analysis of their health anxiety status according to COVID-19 and their training status are presented in Table 5. According to the results of the statistical analysis, it was found that there were no statistically significant differences in the mean scores of general anxiety in the comparisons of the participants' for gender, COVID-19 fear, chronic disease, acute disease, training status, training style and performance status $(p>0.05)$. However, in the comparisons made for COVID-19 test and symptoms, there were statistically significant differences between anxiety score averages $(\mathrm{p}<$ of the statistical analysis, it was found that there were no statistically significant differences in general anxiety score averages in the comparisons of the participants' gender, COVID-19 fear, chronic disease, acute disease, training status, training style and performance status $(\mathrm{p}>0.05)$. However, in the comparisons made for COVID-19 test and symptoms, there were statistically significant differences between anxiety score means $(\mathrm{p}<0.05)$. The overall health anxiety scores of the participants who were tested for COVID-19 and learned that the result was negative (16.33 \pm 3.8) were found to be significantly higher than those who were not tested $(10.13 \pm 4.2)[\mathrm{MD}=6.20, \mathrm{z}=-5.88, \mathrm{p}<0.01]$. Also, the participants who stated that they had COVID-19 disease symptoms $(13.36 \pm 4.6)$ were found to have a significantly higher general health anxiety than the participants who did not have symptoms $(10.39 \pm 4.4)[\mathrm{MD}=2.97, \mathrm{z}=-2.979, \mathrm{p}=0.003]$.

The coronavirus anxiety states based on the general characteristics of the participants, COVID-19 and training status are presented in Table 4. According to the results of the statistical analysis, it was found that there were no statistically significant differences in the mean of coronavirus anxiety scores in the comparisons of gender, fear of COVID-19, COVID-19 test, COVID-19 symptoms, chronic disease, acute disease, training status and training style ( $p>$
$0.05)$. The overall health anxiety scores of the participants who were tested negative for COVID-19 $(21.24 \pm 5.3)$ were found to be significantly higher than those who were not tested $(13.98 \pm$ 5.5) $[\mathrm{MD}=7.26, \mathrm{z}=-5.78, \mathrm{p}<0.01]$. In addition, the participants who stated that they experienced COVID-19 disease symptoms $(17.59 \pm 5.1)$ were found to have a significantly higher mean for overall health anxiety compared to the participants who did not have symptoms $(14.29 \pm 5.8)[\mathrm{MD}=3.30, \mathrm{z}=2.557, \mathrm{p}=0.011]$.

\section{Discussion}

The purpose of the study was to examine the effects of the COVID-19 pandemic and the social isolation period on anxiety states of athletes who participated in competitions and matches in various branches in the 2019-2020 season in Turkey. According to the results of the statistical analysis, the mean scale score of the athletes were $10.64 \pm 4.5$ in the health anxiety sub-dimension, $3.93 \pm 2.7$ in the COVID-19 disease anxiety sub-dimension, and $14.58 \pm 5.8$ in the overall scale. There is no existing scoring scale for the evaluation of the health anxiety scale in the literature (19). However, when compared with the results of studies conducted with healthy and sick people in the past; Abramowitz, Olatunji, 
and Deacon (2007) reported in their study that the general health anxiety score average was above 30 in people with psychological health problems including hypochondriac, panic and general anxiety disorder (20). When literature reviews in the field are examined, it was determined that the general health anxiety scores for approximately 18 items in healthy adults were about 12 points (19). When these findings are taken into consideration, it is seen that the health anxiety of the athletes constituting our research group is slightly higher than the healthy people, although it does not require clinical treatment. In this regard, it will be beneficial to provide psychological support to athletes during the period of social isolation and after this period in returning to sports.

The study shows that there is no significant difference between both health anxiety and coronavirus disease anxiety states of male and female athletes. Baxter et al (2013) reported in their review meta-regression analysis studies on anxiety disorders that women with anxiety disorders had a level of anxiety twice as high as men (9). Large-scale epidemiological studies show that young and adult women have a higher risk of anxiety disorders (21). In the literature, studies examining the anxiety status in women and men focused on performance and pre-competition anxiety (22). Some of these studies showed high anxiety levels for women, while some studies reported no difference between men and women. However, in literature, there is no study that reveals a difference in health anxiety levels between male and female athletes. Scientific studies show that participation in sports activities is a factor that increases athletes' coping with stress and anxiety (23). On the other hand, it is possible that athletic women also having sports-related behaviours beneficial for life such as regular physical activity and balanced nutrition like athletic men may have contributed to similar levels of health anxiety as men.

When the anxiety levels of athletes were examined based on their fear of COVID-19, showing symptoms and testing, the health anxiety was found to be higher in the athletes with disease symptoms and testing. Anxiety is expected to be high in athletes who think they have the symptoms of the disease as they think they have the disease. In terms of testing, the fact that the COVID-19 tests are performed in patients who are determined to show disease symptoms is considered to be a consistent result in the individuals who are tested. When the COVID-19 test results are examined, it is seen that the rate of people tested is $10 \%$ and that the test results are negative. However, the interesting finding is that athletes with negative results have the highest mean of health anxiety $(21.24 \pm$ 5.3) compared to the means in other variables. This result may be due to the high tendency to get tested caused by anxiety in athletes with high health anxiety. Another remarkable finding in the study is that contrary to what is expected, there is no significant difference in anxiety levels between athletes who are afraid of getting coronavirus disease and those who think they are not afraid. When we look at the total anxiety scores of the athletes who reported the fear of getting coronavirus disease as little, some and very high, the mean scores of anxiety was approximately 14 points. As to the reason for this situation; even though most of the athletes stated that they were a little afraid of the disease (55.7\%), the higher anxiety scores of those who stated that they were very afraid (24.1\%) indicate that the athletes may be afraid to state that they are afraid of the disease. This shows that athletes should be examined with scientific methods rather than self-reporting during the coronavirus pandemic process.

When we examined whether the general health status of athletes has an effect on the anxiety status in this period, we found that athletes having or not having chronic or acute illnesses has no effect on health and COVID-19 anxiety in this period. Although catching a disease under normal conditions is a factor that increases anxiety in individuals (24), the low rates of chronic $(10 \%)$ and acute $(9 \%)$ patients in athletes, and chronic diseases 
888-893

Tab. 5. Evaluation of the total health anxiety states of the participants.

\begin{tabular}{|c|c|c|c|c|c|}
\hline \multirow{2}{*}{ Variable } & \multirow{2}{*}{$\mathrm{n}$} & \multirow{2}{*}{$\%$} & \multirow{2}{*}{$\begin{array}{l}\text { Health Anxiety (14 items) } \\
\mathrm{M} \pm \mathrm{SD}\end{array}$} & \multicolumn{2}{|c|}{ Significance } \\
\hline & & & & $\mathrm{Z} / \mathrm{T} / \mathrm{F} / \mathrm{X}^{2}$ & $\mathrm{p}$ \\
\hline \multicolumn{6}{|l|}{ Gender } \\
\hline Female & 99 & $(38.8)$ & $14.15 \pm 5.8$ & \multirow{2}{*}{0.924} & \multirow{2}{*}{0.36} \\
\hline Male & 156 & $(61.2)$ & $14.85 \pm 5.9$ & & \\
\hline \multicolumn{6}{|l|}{ COVID-19 Test } \\
\hline No Test & 234 & $(91.8)$ & $13.98 \pm 5.5$ & \multirow{3}{*}{5.788} & \multirow{3}{*}{$<0.01 *$} \\
\hline Negative & 21 & $(8.2)$ & $21.24 \pm 5.3$ & & \\
\hline Positive & 0 & $(0)$ & - & & \\
\hline \multicolumn{6}{|l|}{ Symptoms of COVID-19 } \\
\hline Yes & 22 & $(8.6)$ & $17.59 \pm 5.1$ & \multirow{2}{*}{2.557} & \multirow{2}{*}{$0.011 *$} \\
\hline No & 233 & (91.4) & $14.29 \pm 5.8$ & & \\
\hline \multicolumn{6}{|l|}{ Fear of COVID-19 } \\
\hline None & 49 & $(19.2)$ & $14.10 \pm 5.7$ & \multirow{3}{*}{0.444} & \multirow{3}{*}{0.64} \\
\hline Some & 142 & $(55.7)$ & $14.88 \pm 5.9$ & & \\
\hline Much & 64 & $(25.1)$ & $14.27 \pm 5.8$ & & \\
\hline \multicolumn{6}{|l|}{ Chronic Disease } \\
\hline Yes & 27 & $(10.6)$ & $14.70 \pm 5.4$ & \multirow{2}{*}{0.119} & \multirow{2}{*}{0.90} \\
\hline No & 228 & $(89.4)$ & $14.56 \pm 5.9$ & & \\
\hline \multicolumn{6}{|l|}{ Acute Disease } \\
\hline Yes & 25 & $(9.8)$ & $15.08 \pm 5.5$ & \multirow[b]{2}{*}{-0.453} & \multirow{2}{*}{0.65} \\
\hline No & 230 & $(91.2)$ & $14.52 \pm 5.9$ & & \\
\hline \multicolumn{6}{|l|}{ Training Status } \\
\hline Regular & 115 & $(45.1)$ & $14.55 \pm 5.9$ & \multirow{3}{*}{1.377} & \multirow{3}{*}{0.50} \\
\hline Irregular & 111 & $(43.5)$ & $14.50 \pm 5.8$ & & \\
\hline No training & 29 & $(11.4)$ & $15.43 \pm 6.1$ & & \\
\hline \multicolumn{6}{|l|}{ Traning Style } \\
\hline With teammates & 57 & $(22.4)$ & $13.77 \pm 5.1$ & \multirow{3}{*}{0.586} & \multirow{3}{*}{0.56} \\
\hline With Personel trainer & 40 & $(15.7)$ & $15.00 \pm 6.2$ & & \\
\hline Alone & 129 & $(50.6)$ & $14.07 \pm 5.7$ & & \\
\hline Athletic Performance Sta & & & & & \\
\hline Serious loss & 65 & $(25.5)$ & $14.00 \pm 5.8$ & & \\
\hline Temporary loss & 88 & $(34.5)$ & $15.57 \pm 5.4$ & & \\
\hline Minor loss & 68 & $(26.7)$ & $13.75 \pm 5.04$ & 1.528 & 0.21 \\
\hline No loss & 34 & $(13.3)$ & $14.76 \pm 7.6$ & & \\
\hline
\end{tabular}

and that this loss is recoverable as the corona virus-related cancellation of sports competitions and races took place $2-3$ weeks before the data collection process. However, higher anxiety levels specific to COVID-19 in athletes thinking a temporary performance loss may be a risk factor for training and performance improvement in the pandemic process. Therefore, in order for these athletes to return to the competitions and races after the pandemic, clubs and coaches should follow the performance and anxiety status of the athletes and make training plans accordingly.

\section{Conclusion}

As a result, COVID-19 disease pandemic and social isolation practices caused anxiety in athletes. Prolonged pandemic and social isolation process may cause anxiety to increase. Increased anxiety in athletes can negatively affect athletic performance both physically and cognitively. Considering the findings of this research, psychological support practices to reduce the anxiety of health and getting coronavirus in this pandemic and social isolation period may contribute to shorter the duration of the return of athletes to competitions and races after the pandemic. mostly being diseases such as hernia and chronic pain, may be the reason for not having a significant difference in health and coronavirus anxiety.

When the training schedule and practices of the athletes during the COVID-19 social isolation period were examined, it was seen that the athletes mostly continued their training (88.6\%) but they did their training on their own (50.6\%). During this period, most of the athletes stated a decrease in their performance $(86.7 \%)$. This indicates that athletes will need an additional preparation training process for participation in competitions and races. When we examine the health and disease anxiety status according to the training and performance status, no significant difference was found although the health anxiety of those who did not train was high. In terms of training practices, there was no difference in the health anxiety status of those who train on their own and those who train with a team or individual trainers. However, it was determined that COVID-19 anxiety levels were higher in athletes stating a temporary loss in performance $(34.5 \%)$ than in the athletes $(26.7 \%)$ who stated that there was a slight decrease in their performance. It is an expected result that athletes do not think that there is a serious loss of performance

\section{References}

1. WHO. Coronavirus disease (COVID-19) outbreak. Emergencies - Dis. 2020 .

2. WHO. Coronavirus Disease 2019 (COVID-19) Situation Report-68.; 2020.

3. Anderson RM, Heesterbeek H, Klinkenberg D, Hollingsworth TD. How will country-based mitigation measures influence the course of the COVID-19 epidemic? Lancet 2020; 395 (10228): 931-934.

4. Hellewell J, Abbott S, Gimma A, et al. Feasibility of controlling COVID-19 outbreaks by isolation of cases and contacts. Lancet Glob Heal 2020; 8(4): e488-e496.

5. Chen S, Yang J, Yang W, Wang C, Bärnighausen T. COVID-19 control in China during mass population movements at New Year. Lancet 2020; 395 (10226): 764-766.

6. Wang C, Pan R, Wan X, et al. Immediate Psychological Responses and Associated Factors during the Initial Stage of the 2019 Coronavirus Disease (COVID-19) Epidemic among the General Population in China. Int J Environ Res Public Health 2020; 17 (5): 1729.

7. Karamustafalığlu O, Yumrukçal H. Depresyon ve anksiyete bozuklukları. Şişli Etfal Hastan Tıp Bülteni 2011; 45 (2): 65-74. 
8. Türkçapar H. Anksiyete bozukluğu ve depresyonun tanısal ilişkileri. Klin Psikiyatr 2014; 4: 12-16.

9. Baxter AJ, Scott KM, Vos T, Whiteford HA. Global prevalence of anxiety disorders: a systematic review and meta-regression. Psychol Med 2013; 43 (5): 897-910.

10. Fernández-Blázquez MA, Ávila-Villanueva M, López-Pina JA, Zea-Sevilla MA, Frades-Payo B. Psychometric properties of a new short version of the State-Trait Anxiety Inventory (STAI) for the assessment of anxiety in the elderly. Neurología (English Edition) 2015; 30 (6): 352-358.

11. Jiang F, Deng L, Zhang L, Cai Y, Cheung CW, Xia Z. Review of the Clinical Characteristics of Coronavirus Disease 2019 (COVID-19). J Gen Intern Med 2020. DOI: 10.1007/s11606-020-05762-w.

12. McCloskey B, Zumla A, Ippolito G et al. Mass gathering events and reducing further global spread of COVID-19: a political and public health dilemma. Lancet 2020; 395 (10230): 1096-1099.

13. Khasnabis C, Heinicke Motsch $\mathrm{K}$, Achu $\mathrm{K}$ et al. Community-Based Rehabilitation: CBR Guidelines. Genova: World Health Organization; 2010. Recreation, leisure and sports; 2010.

14. Gallego V, Nishiura H, Sah R, Rodriguez-Morales AJ. The COVID-19 outbreak and implications for the Tokyo 2020 Summer Olympic Games. Travel Med Infect Dis 2020:101604. https://doi.org/10.1016/j. tmaid.2020.101604

15. Weinberg RS, Gould D. Foundations of Sport and Exercise Psychology Fifth Edition.; 2010.
16. Harriss D, Atkinson G. Ethical Standards in Sport and Exercise Science Research: 2016 Update. Int J Sports Med 2015; 36 (14): 1121-1124.

17. Salkovskis PM, Rimes KA, Warwick HMC, Clark DM. The Health Anxiety Inventory: development and validation of scales for the measurement of health anxiety and hypochondriasis. Psychol Med 2002; 32 (05): 843-853.

18. Aydemir Ö, Kirpinar I, Sati T, Uykur B, Cengisiz C. Sağlik anksiyetesi ölçeği'nin Türkçe için güvenilirlik ve geçerlilik çalişmasi. Noropsikiyatri Ars 2013; 50 (4): 325-331.

19. Alberts NM, Hadjistavropoulos HD, Jones SL, Sharpe D. The Short Health Anxiety Inventory: A systematic review and meta-analysis. J Anxiety Disord 2013; 27 (1): 68-78.

20. Abramowitz JS, Olatunji BO, Deacon BJ. Health Anxiety, Hypochondriasis, and the Anxiety Disorders. Behav Ther 2007; 38 (1): 86-94.

21. McLean CP, Anderson ER. Brave men and timid women? A review of the gender differences in fear and anxiety. Clin Psychol Rev 2009; 29 (6): 496-505.

22. Hamidi S, Besharat MA. Perfectionism and competitive anxiety in athletes. Procedia - Soc Behav Sci. 2010; 5: 813-817.

23. Muhammad KK, Alamgir K, Sami UKSK. Effects of Anxiety on Athletic Performance. Res Investig Sport Med 2017; 1(1): 19-23.

24. Khawar M, Aslam N, Aamir S. Perceived Social Support and Death Anxiety Among Patients with Chronic Diseases. Pakistan J Med Res Pak J Med Res Pak J Med Res Pak J Med Res Pak J Med Res 2013; 52 (3): 75-79.

Received March 30, 2020. Accepted May 23, 2020. 